\title{
PERSONAL AUTONOMY AND THE RIGHT TO TREATMENT: A NOTE ON $R$ (on the application of BURKE) v. GENERAL MEDICAL COUNCIL
}

\section{J K Mason* and G T Laurie**}

Our first reading of Burke ${ }^{1}$ was in The Times ${ }^{2}$ when one's immediate reaction was to question the precise nature of Munby J's judgment - were it and its consequences directed to the specific problems of providing and withdrawing artificial nutrition and hydration (ANH) from dying patients or were the judge's observations and conclusions to be read as being applicable across the whole spectrum of medical care of the terminally ill? Was it indeed the case, unlikely though it seemed, that a right to treatment had been established with scant regard for the attendant resource implications? It was assumed that these questions would be answered when the full transcript was available - and the major aim of this analysis is to discern whether or not this assumption was justified.

\section{Circumstances of the case}

In brief, Mr Burke suffers from spino-cerebellar ataxia, a neurological condition which must attract the deepest possible sympathy from anyone associated with the patient. This is because, while there is progressive and untreatable loss of muscle power and co-ordination, there is no coincident loss of mental ability - the patient is, therefore, fully aware not only of his or her present situation but also of the prognosis. The terminal stages of the illness are best left to description by a court expert:

$[\mathrm{H}] \mathrm{e}$ will by then be bed bound .... He would then become unwell with either a chest or urinary infection and within a few days would become increasingly obtunded .... If medical treatment for the underlying infection is unsuccessful

\footnotetext{
*Professor (Emeritus) of Forensic Medicine and Honorary Fellow, ** Senior Lecturer in Law, Edinburgh School of Law.

${ }_{1} R$ (on the application of Burke) $v$ General Medical Council [2004] EWHC 1879 (Admin), 30 $0^{\text {th }}$ July 2004.

2 Times Law Reports, $6^{\text {th }}$ August 2004.
} 
he would become progressively weaker and semi-comatose and then succumb.' $[5]^{3}$

Mr Burke's anxieties were paraphrased by Munby J:

The claimant wants to be fed and provided with appropriate hydration until he dies of natural causes. He does not want ANH to be withdrawn. He does not want to die of thirst. He does not want a decision to be taken by doctors that his life is no longer worth living. [6]

The basis for these fears lies in the guidance for doctors provided by the General Medical Council. ${ }^{4}$ Paragraph 32 of this pamphlet deals with withdrawal of treatment in a general sense and recommends that, preferably, a senior consultant may make decisions 'taking into account the views of the patient or those close to the patient' [10] while paragraph 38 calls for a second opinion, inter alia, when the views of a patient, not imminently dying but who is seriously ill, cannot be obtained.[11] The guidance also contains a section devoted specifically to providing, withholding and withdrawing artificial nutrition and hydration which can be provided in several ways. Paragraph 81 clearly states that the competent patient may consent to or refuse any intervention of this kind. Separate considerations are introduced in the case of the incapacitated patient according to whether death is, or is not, imminent, and the importance of a team approach, with involvement of those close to the patient and second clinical opinions, is emphasised.[12] Paragraph 82 recommends recourse to the courts in the case of unresolved conflict of opinion.[13] ${ }^{5}$

At the same time, attention was drawn during argument to other paragraphs concerned with treatment in general. These are effectively expressed as a whole in paragraph 42:

\footnotetext{
3 Throughout this paper, numbers in square brackets refer to the relevant paragraph in the transcript. 4 General Medical Council Withholding and Withdrawing Life-prolonging Treatments: Good Practice in Decision Making (2002).

5 Paragraph 83 refers to the required recourse to the courts in England and Wales in the case of patients in the permanent vegetative state: Practice Note (Official Solicitor: declaratory proceedings: medical and welfare provisions for adults who lack capacity) [2001] 2 FLR 158. For Scotland, see Law Hospital NHS Trust v Lord Advocate 1996 SLT 848; G T Laurie and J K Mason 'Negative treatment of vulnerable patients: Euthanasia by any other name ?' [2000] JR 159.
} 
[Y]ou are bound to respect an adult patient's competently made refusal of treatment even where complying with the decision will lead to the patient's death. If a specific treatment is requested which, in your view, is clinically inappropriate, you are not legally or ethically bound to provide it. However, you should give the patient a clear explanation of the reasons for your view, and respect their request to have a second opinion. [16]

The claimant sought declaratory relief on several grounds - in particular that the withholding or withdrawal of $\mathrm{ANH}$, leading to death from starvation or thirst would breach his rights under the European Convention on Human Rights Articles 2, 3 and 8 and would be unlawful under domestic law; that, where a patient had requested $\mathrm{ANH}$, withholding it would be a breach of similar rights; that refusing ANH to a competent patient would be a breach of Article 2 unless providing ANH would amount to degrading treatment under Article 3; that the Guidance, in general, failed to safeguard, and paragraph 81 in particular was incompatible with, those rights; that, in effect, failure to apply the same criteria as pertained in the case of PVS patients ${ }^{6}$ to those not in PVS was discriminatory and contrary to Article 14; and that, where there was disagreement as to withdrawal of $\mathrm{ANH}$, that disagreement should be settled by the court or, alternatively, that patients, relatives and carers should be given the opportunity to secure their rights under Articles 2, 3 and 8

It is, therefore, apparent that $\mathrm{ANH}$ was the prime focus of the application and Munby $\mathbf{J}$ was clear as to his remit. He stated emphatically that he was not concerned with the prioritisation of resources nor was the case about innovative forms of treatment; he also distanced himself from an analysis of professional motivation in end-of life decision making [35]. By contrast, he saw the case as being about:

a form of treatment - ANH - which is relatively simple and straightforward and a routine staple of day-to-day medical practice in hospitals up and down the land [29].

Moreover, he was concerned with the competent rather than the incompetent patient.

6 Fn 4 above. 
[50]. Having thus set the scene for what might appear to be a relatively limited agenda, Munby $\mathrm{J}$ undertook a most extensive and deeply considered analysis of the ethical basis of the law relating to modern day medical treatment. ${ }^{7}$ This proceeded along two lines: an examination of the common law - which has demonstrated increased ethical sensitivity over the last 20 years - and a consideration of the more recently influential Human Rights Act 1998, which incorporates the provisions of the European Convention on Human Rights (ECHR) into domestic law and which is, itself, founded on ethical principles such as sanctity of life (protected by Article 2, ECHR), dignity (which underpins the entire instrument, but is most clearly seen in Article 3, ECHR), and, perhaps less evidently, autonomy or self-determination (which the Strasbourg Court and its domestic counterparts are in the process of 'interpreting out' of Article 8, ECHR which, itself, is concerned, inter alia, with the protection of private life). ${ }^{8}$

We intend to dissect this analysis while all the time urging the reader to consider whether the judgment as handed down by Mumby $\mathrm{J} i s$, indeed, restricted to $\mathrm{ANH}$, and whether it can, in fact, serve as a precedent wholly divorced from resource implications. We will return to consider these points presently.

\section{Ethical and legal fundamentals in the Burke decision}

We could not help being reminded of a comment by an American Supreme Justice in an, admittedly, different context:

A phrase begins life as a literary expression; its felicity leads to its lazy repetition; and repetition soon establishes it as a legal formula indiscriminately used to express different and sometimes contradictory ideas. $^{9}$

\footnotetext{
Drawing very helpfully on the profound analysis by Lord Hoffmann in the Court of Appeal stage of Airedale N H S Trust v Bland [1993] AC 789.

8 The phenomenon of interpreting existing provisions to find new and closely-allied rights is probably best known and illustrated by the Supreme Court of the United States ruling in Griswold v Connecticut 381 US 479 (1965) where the Court 'interpreted' a Constitutional Right to Privacy out of the US Constitution, even although that instrument makes no specific mention of any such right. The rationale is usually that the express provisions are so intimately linked to the protection of say, privacy or autonomy, that they must be interpreted in a manner that directly protects the latter.

9 Tiller v Atlantic Coast Line Railroad Co 318 US 54 (1943) at 68.
} 
We mention this with no disrespect to Munby J. It is simply that the general tenor of Burke v GMC reminds us that medical jurisprudence as a whole is in danger of falling into the trap. What do we mean when we speak of the sanctity of life ? Are we adopting a vitalist attitude implying that life must be preserved at all costs; do we mean, simply, that life should not be deliberately taken away or are we incorporating an element of quality in our definition of sanctity? What do we mean by, say, 'dying with dignity'? The phrase is rapidly becoming synonymous with dying undisturbed by invasive apparatus ${ }^{10}$ although others might hold that to have experts struggling to revive a patient with the use of advanced technology is, itself, a recognition of that person's dignity. ${ }^{11}$ At what point do the interests of the community set a limit to the self-determination of the individual ?

True definitions are hard to come by yet they are essential if a proper balance is to be set between the conflicting ethical imperatives - and achieving that balance lies at the heart of Burke. Indeed, the case is a good illustration of a growing phenomenon in medical law - that is, the attempted marriage of ethical and legal concepts by which to identify the fundamentals of the discipline itself.

\section{Human dignity}

Much space was devoted to a consideration of respect for human dignity which, as we have said, is a difficult concept but one which Munby $\mathrm{J}_{\text {rates highly }}{ }^{12}$ as not being 'a meaningless incantation' but a fundamental recognition of our humanity and a recognition, in particular, of a person's interest in the manner of his or her death. [57] In our view, much of the difficulty would disappear if we reverted to the civil law tradition of equating infringement of dignitas with insult to the personality. ${ }^{13}$ It is, thus, not so much the nature of the treatment given which affects the patient's

\footnotetext{
10 And this seems to be Munby J's general view.

11 Munby $\mathrm{J}$ takes this point at [66] - finding 'the right balance between using undignified means in striving to achieve dignified ends'.

12 Quoting his judgment in $R$ (on the application of $A, B, X$ and $Y$ ) $v$ East Sussex $C C$ and the Disability Rights Commission (No. 2) [2003] EWHC 167(Admin.) at [86].

13 For modern discussion, see J Neethling, J M Potgieter and P J Visser Neethling's Law of Personality (1996), chapter 6. This being the case, it is the concept of dignity which is most likely to impinge on Article 8 of the Convention on Human Rights.
} 
dignity but, rather, whether the treatment offends the patient's personality as being either against his interests or contrary to his autonomous choice.

Dignity can, of course, be seen from a subjective or objective perspective, and both feature in Munby's analysis. They divide along the categories of competency. Thus, it is for the competent patient to decide - and we should note with care the use of this expression - “... what treatment should or should not be given in order to achieve what the patient believes conduces to his dignity and in order to avoid what the patient would find distressing" [emphasis added] [130] Where the patient is incompetent, best interests applies, and the dignity test is what "right-thinking persons" would consider undignified in such circumstances [149].

The legal justification offered for this position is a combined 'pincermovement' from Articles 3 and 8 of the ECHR. While Article 3 protects both competent and incompetent persons from inhuman and degrading treatment, Article 8 embodies the essence of the principle of autonomy, which “...embraces such matters as how one chooses to pass the closing days and moments of one's life and how one manages one's death". [62-63] ${ }^{14}$ So autonomy is about choice, which we know well. But the legal basis offered for, and the significance of, this approach are both intriguing and worrying. We offer three observations. First, the legal underpinning of this view of autonomy involves rulings which were about choices to die, not choices to live. ${ }^{15}$ The attendant obligations were largely negative in nature - obligations not to interfere with choices about when and how to die - rather than as in the current position which seems to import a positive obligation to intervene because the patient wants it. Moreover, while it is true that these decisions lauded the importance of protecting personal autonomy, there is no mention in Burke of the fact that the claimants failed in both of the precedents cited because of wider considerations. Second, and relatedly, there is very little mention of any such wider considerations in the instant case. Although Article 3 contains an absolute, unqualified right to dignified treatment, the same is not true of Article 8, which contains express provisions that allow the fundamental right to respect for private life to be limited, inter alia, for the

\footnotetext{
14 Quoting from Pretty $v$ United Kingdom (2002) 35 EHRR 1; Rodriguez v Attorney General of Canada [1994] 2 LRC 136.

15 Fn 14 above.
} 
protection of health or morals or the protection of the rights and freedoms of others. ${ }^{16}$ Munby J even talks of the 'absolute nature' of the right to respect for autonomy and self-determination.[75] We suggest, however, that this uncompromising interpretation currently attracts no support in either ethics or law, save in the context of refusal of treatment, which is not at issue in this case. Finally, we wonder about the consequences of this ECHR duet between Articles 3 and 8. Why, for example, is it not sufficient to argue that withdrawal of AHN is prima facie a breach of Article 3, as we would agree? Why also rely on Article 8? One answer might be that, as Munby $\mathbf{J}$ acknowledges, the test for severity of treatment under Article 3 has a high threshold; it is, moreover, often tied to intentionally harmful conduct. Article 8, however, ushers in the value and importance of the views of the patient, and this is enough to tip the balance in favour of what the patient wants. The net result is typical of a more general movement in medical law to prioritise autonomy over other considerations. This is something which continues to concern us and which we have lamented elsewhere. ${ }^{17}$ The most worrying aspect, however, is that Munby J's use of the language of determinism implies that, as a matter of law, what the patient wants is what the patient should get. We explore this further below.

\section{Best interests}

Dignity and best interests are entwined and the judgment in Burke contains a lengthy analysis of the latter. Here, we suspect that Munby J's main anxiety is to confine the doctor's role in decision-making and this is understandable insofar as, as we have noted, he was concerned in the main with the competent patient. But, in leading with the, now, well-known statement of Butler Sloss P:

Best interests are not limited to best medical interests, ${ }^{18}$

he moved into the field of the incompetent and out of that of autonomous choice. Moreover, he followed this with an analysis of, and reliance on, two seminal cases

\footnotetext{
16 'There shall be no interference by a public authority with the exercise of this right except .... for the protection of health or morals, or for the protection of the rights and freedoms of others'.

17 See, in general, J K Mason, R A McCall Smith and G T Laurie Law and Medical Ethics (6 ${ }^{\text {th }}$ ed., 2002), para 1.20 .

18 In Re MB (an adult: medical treatment) [1997] 2 FLR 426 at 439. The case concerned refusal of life-saving treatment.
} 
involving sterilisation of the incompetent. ${ }^{19}$ Thus, the subjects in these cases were not afflicted with physical disease and, inevitably, their 'interests' were essentially their welfare interests. We take leave to doubt if a case such as Re A, concerning sterilisation of a Down's syndrome boy, is a good precedent for one involving a life and death decision. Even so, the tone of these two judgments can be summed up in the words of Butler Sloss P that 'best interests encompasses medical, emotional and all other welfare issues' and Munby J extrapolated this:

The short point is that doctors can properly claim expertise on medical matters; but they can claim no special expertise on the many non-medical matters which ... go to form the basis of any decision as to what is in patient's best interests. [94]

He did, however, go what seems to be a considerable distance further:

It follows from this that medical opinion, however eminent, can never be determinative of what is in a patient's best interests ... If the patient is incompetent and has left no binding and effective advance directive then in the final analysis it is for the court to decide what is in his best interests.[93] (emphasis added)

Read baldly, this appears to say that a doctor should seek court approval of every decision he takes in relation to an incompetent patient and this cannot be so. We are reminded of Lord Brandon's statement of the common law position:

The lawfulness of a doctor ... giving treatment to an adult patient disabled from giving consent will depend not on any approval or sanction of a court but on the question whether the ... treatment is in the best interests of the patient concerned. That is, from a practical point of view, just as well, for, if every ... treatment to be given required the approval or the sanction of the court, the whole process of medical care for such patients would grind to a halt. $^{20}$

19 In re S (adult patient: sterilisation) [2001] Fam 15; Re A (male sterilisation) [2000] 1 FLR 549.

$20 \operatorname{Re} F[1990] 2 \mathrm{AC} 1$ at 56. 
This undoubtedly stands as a matter of law. But it must now be read in light of Munby J's importation of a test of 'right thinking persons' and how they would consider the best interests of, and the dignified (or otherwise) state of, the incompetent patient.

\section{Sanctity of life}

In fact, we find much of this part of the judicial argument confusing as it is, as admitted, ${ }^{21}$ related to best interests in general. In respect of ANH in particular, Munby $\mathrm{J}$ is clearly suspicious of the several cases he quotes which seek, progressively, to modify the concept of the sanctity of life in favour of one which admits of a value judgment; his starting point, as he says, lies in the very strong presumption in favour of taking all steps which will prolong life - 'Save in exceptional circumstances, or where the patient is dying, the best interests of the patient will normally require such steps to be taken'.[100]

This is a near vitalist approach which, as a generalisation, is hard to sustain whether one measures 'best interests' in holistic or purely medical terms. Even so, if the doctor's clinical acumen is to be rejected as a measure of 'exceptional circumstances', one must have some bench mark at which the sanctity of life gives way to the principle of best interests - and Munby $\mathrm{J}$ seizes upon 'intolerability of life' as his touchstone. It is here that we, with the greatest respect, would wish to take issue with the learned judge.

In the first place, his comparator cases all deal with physical disease for which treatment is available but has failed and in which tolerability is measured by tolerance to pain. The test as it has been applied has been directed to the relief of suffering and involves the cessation of treatment of the underlying condition often also including recourse to the doctrine of double effect - a doctrine which can scarcely apply to fatal neurological disease. Withdrawal of ANH in this latter circumstance is, we suggest, in a different category. The prospect of removing ANH from a conscious patient against his or her will is beyond contemplation; indeed, as Munby $\mathbf{J}$

21 At para [98]. 
accepts[173], it is virtually impossible to foresee removal of such a basic resource from anyone other than the patient who has passed into irrecoverable unconsciousness. $^{22}$ He broaches this issue as a rider to his legal analysis. Thus, he foresees that entitlement to care may be altered in the case of a permanently comatose, moribund patient [174-176] and that it will be lawful to remove ANH in such cases if the medical assessment indicates that it would be futile to continue to provide it.

The use of the language of futility, however, simply reinforces our central point: whether the life of an insensate patient is couched in terms of 'quality', 'tolerability' or 'futility', the assessment is still a matter of clinical judgment. Insofar as that judgment, in the circumstances, is, essentially, as to when further medical treatment becomes futile, this keynote aspect of the Burke decision seems to us not even to move the goalposts in the decision-making field; at most, it lengthens the pitch.

As for the competent patient, or the incompetent who has expressed him or herself by way of a valid advance directive, it is of crucial importance to note that Munby J lays his cards on the table when it comes to balancing or prioritising ethical and legal principles. He states categorically: 'Important though the sanctity of life is, it has to take second place to personal autonomy; and it may have to take second place to human dignity'. [80]

\section{Patient autonomy}

There is, in fact, surprisingly little to say about the competent patient if the ratio in Burke is concerned only with ANH. In practical terms, it is, as has been mentioned already, almost impossible to conceive of the non-consensual withdrawal of ANH from the sensate subject. The issues then become simply that of patient autonomy - and, even more narrowly, given the ambience, patient autonomy as

\footnotetext{
22 It is for this reason that we have questioned even the minimal exceptions to the rule expressed in the British Medical Association's Withholding and Withdrawing Life-prolonging Treatment: Guidance for Decision Making (2nd ed., 2001) quoted at [112]. See G T Laurie and J K Mason 'Negative treatment of vulnerable patients: Euthanasia by any other name ?' [2000] JR 159. It is fair to say that Munby $\mathbf{J}$ recognises much of this - see, for example [214f].
} 
expressed through an advance directive - and that of the extent to which the exercise of that autonomy should be the determinant of medical treatment. But it is precisely this aspect of the ruling that is worrying because of its unlooked-for, and yet potentially far-reaching, consequences.

The exercise of autonomy in the medical setting is generally interpreted in a negative sense - that is, as expressing the patient's right to refuse treatment. The starting point here is surely, because of its uncompromising tone, Butler Sloss $\mathrm{P}$ in $R e$ $M B:$

A mentally competent patient has an absolute right to refuse or consent to medical treatment for any reason, rational or irrational, or for no reason at all, even where the decision may lead to his or her own death. ${ }^{23}$

- and there is little doubt as to Munby J's endorsement of the President's views. ${ }^{24}$ Whether this principle can maintain its overarching status for all time, is, however, a matter of doubt. The hubris of autonomy is fast becoming conflated with egotistical hedonism and, at some stage, the communitarian ethos must be revisited. The law takes a serious view of death and so does the public - by and large, it is a legal and ethical area where the great majority of persons want certainty. We should think carefully before allowing obeisance to autonomy cloud an area in which crystal clarity is needed.

\section{The meaning of Burke}

This ruling leaves us with two fundamental areas of doubt - first, does it require that care be given on demand?, and second, does it require that individual doctors be obligated to provide that care?

The most important feature of the case is that it seems to extend the concept of patient autonomy to a positive right to require treatment - and we will return to this

\footnotetext{
23 Fn 18 above.

24 See, for example, para [80].
} 
presently. As for the position of doctors, we are reminded of the words of Balcombe $\mathrm{LJ}$ in a case which is extensively considered in Burke at paras 181 et seq:

I agree with Lord Donaldson MR that I can conceive of no situation where it would be proper ... to order a doctor, whether directly or indirectly to treat a child in a manner contrary to his or her clinical judgment ${ }^{25}$

which can, of course, be extrapolated to the terminally ill adult. Certainly Munby J appreciates that this is the extant position but he distinguishes Burke from $\operatorname{Re} J$ on several counts - perhaps most importantly in that the latter was heard in the Family Division whereas the current case is one for judicial review in the Administrative Court. He preferred to see the instant case as depending on the fact that the hospital doctor who has admitted a patient undertakes a continuing duty of care [85] - which persists, at least, until the patient's life is 'intolerable'. Moreover, while no individual doctor can be required to provide treatment that offends his or her professional judgment, the law none the less requires that the hospital authority find another health care professional who is willing to discharge this continuing duty of care. But it is only when we ask: what is the scope of this duty?, that we understand the full implications of Munby's adherence to the autonomy mantra. For, as the learned judge said, the patient's decision 'as to what life-prolonging treatment he should or should not have is in principle determinative'. [116(11) emphasis added]. And here we come again to our repetitive difficulty - what treatment is Munby J contemplating ? Thus far, there is nothing to suggest that he is being exclusive. When we come to paras 167 et seq, however, he is using almost identical language but in relation to ANH alone - and it is easy, and coherent, to agree with what is said in one context but to reject it in the other. In essence, the latter demands no more than what many would describe as basic care rather than treatment and problems of resource allocation, although not irrelevant, are minimalised.

This, in turn, draws attention to what many would see as an insufficient emphasis in the judgment as to the reasons why and how we should distinguish between $\mathrm{AHN}$ as basic care and other forms of treatment. The risk is that later courts

$25 \operatorname{Re} J$ (a minor) (medical treatment) [1993] Fam 15 at 29. 
will not do so. We need only consider the position post-Bland. ${ }^{26}$ The House of Lords was emphatic that that case provided a precedent only for others concerning patients in persistent vegetative state (PVS), yet a series of subsequent rulings slowly extended it to other medical conditions, and undermined the intended precedent as a result. ${ }^{27}$ If the House of Lords cannot hold the line in a negative treatment decision, what will flow from a High Court ruling which, it would seem, purports to create a positive right to care?

\section{Our rights and their consequences}

There is, of course, the prospect of an appeal in this case - especially if the ruling, indeed, embodies a right to treatment. ${ }^{28}$ But does it do so? On one interpretation the case might merely give the patient a right to judicial review of a decision to withdraw essential, life-sustaining care. Thus, it may merely re-enforce recent decisions that seek to minimise the monopolistic medical hold over care decisions. ${ }^{29}$ As Munby $\mathbf{J}$ states: 'There is an obligation to refer such cases to the court. That obligation arises under Article 8.....[W] hat was previously only a matter of good practice is now .... a matter of legal requirement' [210]. ${ }^{30}$ Yet, he also points out that 'no one has suggested that [the case] has any significant cost implications' [29]. This does not reflect reality. The costs of providing even basic care, over a sustained period of time, and with attendant staffing costs, must represent a significant impact on the finite resources of a national health service. Thus, even if it is possible to contain this precedent within the parameters of $\mathrm{ANH}$, it can never be divorced from its inherent fiscal consequences. That these have been ignored arises from the highly individualistic, psuedodeontological approach to patients' rights that has made autonomy a trump card and which ignores the wider impact of the decision. Moreover, we are concerned that this contains elements which suggest entitlement to care in general, implying a right to that care, and not simply a claim to judicial consideration of the arguments. These

\footnotetext{
26 Fn 7 above.

27 J K Mason and G T Laurie 'The management of the persistent vegetative state in the British Isles' [1996] JR 263.

${ }_{28}$ We need only consider the quite remarkable speed with which the Court of Appeal heard the Child B appeal $-R v$ Cambridge Health Authority, ex p B [1995] 2 All ER 129.

29 See, for example $\operatorname{Re} A$, fn 19 above and $\operatorname{Re} M B$, fn 18 above.

30 The possibility envisaged in Burke is subsumed under 'such cases' by reason of para 202(c) 'where there is evidence that the patient when competent would have wanted ANH to continue in the relevant circumstances'.
} 
elements include the linking of autonomy-based arguments under Article 8 of the ECHR with dignity-based arguments under Article 3, thereby mandating a subjective approach to dignity in law. The case sends the message that the patient's views are determinative of his interests, even when those interests are in favour of care. If this is indeed the case, why should the nature of the care in question matter at all? We suggest that a decision which is based on such fundamental principles - which themselves are designed to be of general application - cannot apply in some cases and not in others when the principle of overriding importance is respecting what the patient wants. But it need not have been thus. The same position could have been reached via a dignity-based analysis by arguing, for example, that to remove such basic care as feeding and hydration is - objectively assessed - an affront to human dignity and that a continuing obligation to provide such care is required. But to embrace so completely an individualistic rights-based approach to the question gives a particularly powerful slant to the answer that is given. And, in so doing, it sets a very dangerous precedent.

\section{Conclusion}

In conclusion, we find it hard to see just what Burke has achieved in general terms.

The judgment includes an exhaustive and erudite analysis of the law as it stands. Yet, despite the ultimate findings, it is difficult to see in what respect the GMC's guidelines conflict with the law - such deficiencies as are cited appear to be more those of omission rather than commission. It is even harder to envisage competent medical practitioners undertaking treatment that is so paternalistic as to be contrary to the overall spirit of the opinion in Burke - and Munby J, himself, concedes this at many points. If the precedent is restricted to a ruling on the legality of these guidelines, then one cannot help but regard the judgment as doing much more than tilting at windmills.

The exception to this generality lies in what seems to us to be a fundamental diversion from precedent - that the patient has a right to require treatment. While this may well command majority support in respect of the provision of $\mathrm{ANH}$, we cannot see that it can, in practical terms, be extended to treatments of all types - but this is the inevitable interpretation of Munby J's conclusions at para $213 \mathrm{~m}$. In the end, we 
have to confess to finding this decision unsatisfactory. The failure to distinguish clearly between arguments devoted to the treatment terminal illness in general and provision of ANH in particular serves only to muddy what were, previously, relatively clear waters. It would be disastrous were Burke to precipitate a flood of actions demanding a right to expensive or experimental treatments designed to ward off inevitable death without providing any recognisable benefit. ${ }^{31} \quad$ Burke could either raise the hopes of many terminally ill patients to improbably high levels or it could achieve little more than a revised wording of professional guidelines which, even as they stand, pose little or no threat to either good medicine or good law.

31 One wonders, for example, whether cases such as that of child B would be decided differently as a result: $R v$ Cambridge Health Authority, ex p B [1995] 2 All ER 129. 